
\title{
25 Research Soure \\ Further delineation of the phenotypic spectrum of pathogenic variants in MED13
}

\section{Inna S. Povolotskaya ( $\nabla$ ipovolotskaya@gmail.com )}

Pirogov Russian National Research Medical University: Rossijskij nacional'nyj issledovatel'skij medicinskij universitet imeni N I Pirogova https://orcid.org/0000-0001-6621-232X

\section{Natalya V. Vetrova}

Center of genetics and reproductive medicine "Genetico" Ltd

\section{Svetlana O. Zhikrivetskaya}

Center for genetics and reproductive medicine "Genetico" Ltd

\section{Elizaveta V. Musatova}

Center of Genetics and reproductive medicine "Genetico" Ltd

\section{Valeriia S. Klestova}

Center of genetics and reproductive medicine "Genetico" Ltd

\section{Natalya A. Shirokova}

Center of genetics and reproductive medicine "Genetico" Ltd

\section{Aleksandra A. Tveleneva}

Center of genetics and reproductive medicine "Genetico" Ltd

llya N. Kotov

Center of genetics and reroductive medicine "Genetico" Ltd

\section{Artur A. Isaev}

Center of genetics and reproductive medicine "Genetico" Ltd

\section{Ekaterina A. Pomerantseva}

Center of genetics and reproductive medicine "Genetico" Ltd

\section{Research}

Keywords: Neurodevelopmental disease, Speech delay, Autism, Epilepsy, Incomplete Penetrance, Whole exome sequencing, Array comparative genomic hybridization, FMR1

Posted Date: September 20th, 2021

DOl: https://doi.org/10.21203/rs.3.rs-910435/v1

License: (c) (i) This work is licensed under a Creative Commons Attribution 4.0 International License. Read Full License 


\section{Abstract}

\section{Introduction:}

Diagnostic yield of the genetic testing in search for the molecular basis of neurodevelopmental diseases remains low due to incomplete knowledge of the phenotypic spectrum of pathogenic variants in a specific gene. Recently the MED13 gene was linked to neurodevelopmental disease.

\section{Methods:}

Four families with children affected by autism spectrum disorder (ASD) were recruited to the study. Extensive genetic testing was performed for each proband: CGG repeat expansion analysis in FMR1 gene; whole exome sequencing (WES); array comparative genomic hybridization (aCGH); maternity and paternity confirmation. Genetic variants which were revealed by WES were verified with Sanger sequencing or aCGH in probands and their relatives.

\section{Results:}

Four rare heterozygous genetic variants in MED13 gene were identified in four unrelated patients with clinical features matching MED13-associated phenotype: intellectual disability (ID) of various degrees, speech delay, ASD and mild facial dysmorphisms. Three of the variants occurred de novo, while one was inherited maternally, in accordance with previous findings, suggesting incomplete penetrance. A patient with a de novo missense mutation in the intrinsic disordered region of MED13 developed seizures similarly to the only other reported patient with a pathogenic missense variant in this region.

\section{Limitations:}

Additional functional studies are needed to elucidate molecular mechanisms of the disease and distinguish between pathogenic and non-pathogenic variation.

\section{Conclusion:}

Our data strongly support the role of MED13 in neurodevelopmental disease by eliminating other common genetic defects. We expand the phenotypic spectrum of the disease causing variants: pathogenic missense variants in the intrinsic disordered region of MED13 may lead to a phenotype with seizures and incomplete penetrance of the maternally inherited variants may occur.

\section{Background}

Neurodevelopmental disorders (NDDs) form a large heterogeneous group of disorders that affect development of the nervous system and may manifest as intellectual disability (ID) of various degrees, autistic features and difficulties in emotional regulation among other features [1]. NDDs affect more than $1 \%$ of the general population in developed countries [2] and have a dramatic impact on their health 
systems and economies [3, 4]. Genetic testing and genetic counseling of the families affected by NDDs are extremely important in order to improve their quality of life and reduce the economic burden on the health systems [5].

More than 250 genes are known to cause NDDs [6], but the diagnostic yield of the genetic testing is still around $36 \%$ [7]. In big part it is a result of incomplete knowledge of the molecular basis of this class of disorders and fragmentary characterization of the phenotypic spectrum of the pathogenic variants in specific genes [1].

Recently, pathogenic genetic variants in genes encoding mediator complex subunits CDK8 [8], MED12 [9, 10, 11], MED13 [12], and MED13L [13, 14] were linked to phenotypically overlapping forms of NDDs. In particular, Lot Snijders Blok and colleagues identified a link between pathogenic variants in MED13 and ID with autistic features with strong evidence of MED13 variants pathogenicity [12].

Here we report four additional cases of patients with damaging genetic variants affecting MED13 with different levels of ID and autistic features. Interestingly, three patients were initially referred to the center as cases of isolated autism spectrum disorder (ASD). Other phenotypic features of these patients, which are common for MED13-associated developmental disorder, were identified during reverse-phenotyping.

\section{Methods}

\section{Patients}

Three families were recruited to the study after obtaining written informed consents from the participants during genetic counseling session (Fig. 1). Peripheral blood samples were obtained from probands, their parents and other relatives (All3, All4, All13, Al3, Al4, Alll4, Bll5, Bll6, Blll9, Cll2, Cll3, CIII1). DNA was extracted from peripheral blood samples with QIAamp DNA Blood Mini kit (Alll3, Al3, Al4, Alll4, BII5, BIII9, CIII1) and innuPREP Blood DNA kit (All3, All4, BII6, CII2, Cll3).

In the course of the study the following genetic tests were performed for probands AllI3, BIII9 and CIII1:

1. $C G G$ repeat expansion in $F M R 1$ gene;

2. Whole exome sequencing (WES);

3. Array comparative genomic hybridization (aCGH);

4. Sanger verification of the genetic variants revealed by WES for probands and their parents;

5. Maternity and paternity confirmation.

The fourth family was recruited to the study after receiving results of the WES in our centre. For this family we also obtained written informed consent during a genetic counseling session (Fig. 1). Peripheral blood samples were collected from the proband and the parents (DI1, DI2, DII2). DNA was extracted from peripheral blood samples with innuPREP Blood DNA kit (DI1, DI2, DII2).

The following genetic tests were performed for the proband (DII2): 
1. Whole exome sequencing (WES);

2. aCGH verification of the deletion revealed by WES for the proband and his parents;

3. Maternity and paternity confirmation.

\section{CGG repeat expansion analysis in FMR1 gene}

CGG repeat expansion analysis in FMR1 gene was performed according to previously described protocol [15]. The primer sequences are listed in Supplementary Table 1. Capillary electrophoresis was run for all samples on 3130xl Genetic Analyzer.

\section{Exome sequencing}

DNA concentration was measured using Qubit dsDNA HS Assay kit on Qubit 2.0. Ultrasound DNA fragmentation was performed with ME220 Focused-ultrasonicator to form DNA fragments with mean length of $150 \mathrm{bp}$. WES library preparation was performed with SureSelect Human All Exon V7 kit according to the manufacturer instructions. Library validation was performed on TapeStation 4200 . Libraries were sequenced with NovaSeq 6000.

\section{Bioinformatic analysis and variant filtering}

Sequencing reads were adaptor- and quality-trimmed with seqpurge [16], mapped to hg19 with bwa-mem [17], deduplicated with samtools [18] and locally reassembled in the target space with abra2 [19]. Genetic variants were called with FreeBayes [20] and annotated with Ensembl Variant Effect Predictor [21]. CNV analysis was performed with the EXCAVATOR2 algorithm [https://pubmed.ncbi.nlm.nih.gov/27507884/]. Variants were filtered based on its gnomAD [22] filtering frequency with frequency cutoff of $0.1 \%$. Only variants in the exonic space and variants predicted to affect splicing were considered. Variant interpretation was performed according to ACMG guidelines [23].

\section{aCGH}

aCGH for Alll3, BIII9, CIII1 and DII2was performed with SurePrint G3 ISCA v2 CGH + SNP 4x180K Microarray according to the manufacturer's recommendations. aCGH for DI1 and DI2 was performed with GenetiSure Pre-Screen 8x60K Microarray. The data were analyzed with CytoGenomics v.5.0.2.1.

\section{Sanger sequencing}

The polymerase chain reaction (PCR) amplification was performed with specific primers, reported in Supplementary Table 2.

The first amplification round was performed with BETAQ-1000 Bullseye Taq DNA Polymerase. PCR products were run on the $2.5 \%$ agarose gel and visualized under ultraviolet transilluminator. Sequencing was performed using BigDye ${ }^{\mathrm{TM}}$ Terminator v1.1 Cycle Sequencing Kit and amplification primers. 3130XI Genetic Analyzer instrument was used for capillary-based sequencing of DNA from samples (All3, All4, Alll3, Al3, Al4, All14, BII5, BII6, BIII9, CII2, CII3, CIII1).

\section{Maternity and paternity confirmation}


Maternity and paternity confirmation was performed with the "COrDIS Plus» kit according to the manufacturer's recommendations. Capillary electrophoresis was run for all samples with $3130 \mathrm{xl}$ Genetic Analyzer.

\section{Allele specific expression analysis}

Total RNA from whole blood was extracted using QIAamp RNA Blood Mini Kit (Qiagen). The total RNA concentration was determined using the Qubit RNA BR Assay Kit (Thermo Fisher Scientific) on a Qubit 2.0 Fluorometer (Thermo Fisher Scientific). The integrity of each RNA sample was assessed using $2 \%$ agarose gel electrophoresis. For each sample, $0,5 \mu \mathrm{g}$ total RNA was used for the production of cDNA by QuantiTect Reverse Transcription Kit (Qiagen). cDNA of All3, All4, Alll3 were diluted 50 times. For the standard curve, a 5 -fold, 10 -fold, and 100-fold dilution of cDNA with the mutant allele was used. The multiple qPCR reaction was performed in a $25 \mu$ reaction volume containing $1 \times$ HS-qPCR Buffer (BiolabMix), 5 pmol of each primer and $2.5 \mathrm{pmol}$ of each probe listed in Supplementary Table 3. Each qPCR reaction was amplified in triplicate. Real-time PCR amplification was run on the CFX96 Touch (BioRad). After initial denaturation at $95^{\circ} \mathrm{C}$ for $5 \mathrm{~min}$, the reactions were run for 50 cycles at $95^{\circ} \mathrm{C}$ for $15 \mathrm{~s}$ and $62^{\circ} \mathrm{C}$ for $30 \mathrm{~s}$. Quantification cycle values (Cq) for MED13 yielded by qPCR were normalized to GAPDH used $2^{-\Delta \Delta C T}$ method.

\section{Results}

Clinical features of the patients are summarized in the Table 1.

\section{Family A}

Patient A was referred to the center at the age of 4 years with the diagnosis of ASD, which was established at 2 years and 6 months. The patient presented with mild cognitive deficit and speech delay, mainly receptive language disorder and absence of phrasal speech. Medical examination revealed a set of facial dysmorphic features: deeply set eyes, wide nose, high anterior hairline, low set ears, broad and flat philtrum and pointed chin. Early motor development was normal, as well as EEG-screening. The patient did not have any eye/vision, heart abnormalities or other chronic diseases. Family history examination revealed that the patient's maternal cousin (III6) also had a speech delay.

Using WES a deletion of two amino acids (p.T292_P293del) with unknown clinical significance was identified in MED13. This variant was located in the N-terminal domain of the MED13 protein along with the majority of the pathogenic variants identified so far in this gene (Fig. 2). The variant was predicted to affect protein function by PROVEAN algorithm [24] and was absent from the gnomAD database [22]. Sanger sequencing revealed that this variant was inherited from the unaffected maternal grandmother via the unaffected mother (Supplementary Fig. 1). DNA from the affected maternal cousin was not available for testing. Allele specific expression analysis of the RNA samples from the unaffected maternal grandmother, the unaffected mother and the proband didn't reveal any allele expression shift in 
the unaffected family members (Fig. 3, Supplementary Supplementary Fig. 2 for the standard curve data).

No other potentially causative genetic variants were found in this family.

\section{Family B}

Patient B was referred to the center with ASD at the 4 years of age. The patient presented with cognitive deficit (borderline IQ 92) and speech delay: absent since the age of 18 months expressive speech, receptive language disorder, dysarthria. The patient had attacks of aggression and autoaggression, neutropenia and a set of dysmorphic features: short palpebral fissures, wide nose, broad and flat philtrum, thin upper lip, pointed chin and high anterior hairline. At the age of 2 years the patient was diagnosed with focal cryptogenic epilepsy. EEG imaging showed generalized periodic epileptiform discharges during sleep. MRI imaging revealed ventricular asymmetry and a lower placement of the cerebellar tonsils. The patient has been seizure-free with Levetiracetam and Topiramate since 3 y.o. Patient's early motor development was normal.

WES revealed the presence of a missense variant p.Asp358Asn, which was later shown to occur de novo by Sanger sequencing with both maternity and paternity confirmed (Supplementary Fig. 1). The variant was absent from the gnomAD database,[22], located in the N-terminal domain of the MED13 protein at the highly conservative position and was predicted to affect protein function by several computational algorithms (SIFT, MetaSVM). The variant was classified as likely pathogenic according to ACMG guidelines [23].

No other potentially causative genetic variants were found.

\section{Family C}

Patient $\mathrm{C}$ was referred to the center at the age of 5 years. The patient presented with moderate cognitive deficit, delayed expressive and receptive language, dysarthria. The patient was diagnosed with ADHD at the age of 3 years. MRI imaging revealed nonspecific changes: zones of leukopathy and expanded perivascular spaces in the periventricular white matter of the parieto-occipital regions. The patient had several dysmorphic features: deeply set eyes, short palpebral fissures, epicanthus, wide nose, depressed nasal bridge, broad philtrum and high anterior hairline. Early motor development and EEG imaging were normal. The patient did not have any eye/vision, heart abnormalities or other chronic diseases.

The variant p.Ser2127Ter was detected by WES and shown to occur de novo by Sanger sequencing with both maternity and paternity confirmed (Supplementary Fig. 1). This variant was located in the C-terminal domain of the MED13 protein in the penultimate exon 12 nucleotides upstream to the splice donor site of the MED13 gene and was not predicted to lead to the nonsense mediated decay. Nevertheless, two missense pathogenic variants (p.Q2060K and p.A2064V) in the C-terminal of the protein were annotated previously [12], which provides evidence of the functional importance of this region. The variant 
p.Ser2127Ter was absent from the gnomAD database and classified as likely pathogenic according to ACMG guidelines [23].

No other potentially causative genetic variants were found in this family.

\section{Family D}

Patient D was referred to the center at the age of 3,5 years for WES. During WES a pathogenic deletion, spanning MED13 was discovered and the patient was recruited to the current study.

The patient presented with speech delay and ADHD. His vocabulary was limited to 50-60 words and the phrasal speech was absent. The patient was diagnosed with sensorineural hearing loss at the age of 3 months but the hearing loss did not progress. Medical examination revealed a set of facial dysmorphic features: wide nose, high anterior hairline, high forehead, low set ears, broad and flat philtrum, pointed chin, thin lips. Early motor development was normal. The patient did not have any heart abnormalities nor EEG changes.

The variant seq[GRCh37]del(17)(q23.2)chr17:g.58093980_60332766del was detected by WES and shown to occur de novo by aCGH (arr[GRCh37]17q23.1q23.2(58066792_60315303)x1) with both maternity and paternity confirmed (Supplementary Fig. 3). This $2.2 \mathrm{Mb}$ deletion was absent from the gnomAD database [22], and curated catalogue of human genomic structural variation DGV [25], and involves 13 genes including 6 morbid genes (CA4, PPM1D, TBX2, TBX4, BRIP1, MED13). The similar coordinates deletions are annotated in the Decipher database [26], as pathogenic or likely pathogenic. The 17q23.1-q23.2 deletion is known to cause a NDD with similar phenotypic features (OMIM: 613355, ClinGen: ISCA-37501, ORPHA: 261279) [27, 28, 29, 30]. According to the current standards for the interpretation and reporting of constitutional CNVs, the detected variant should be classified pathogenic, since it overlaps the region with established haploinsufficiency (Suggested points-1) [29].

No other potentially causative genetic variants were found in this family.

\section{Discussion}

MED13 is a subunit of Mediator complex, an evolutionarily conserved protein complex required for assembly and stabilization of the pre-initiation complex during transcription initiation [31]. This complex is the link between different transcriptional factors' signals and RNA polymerase II [31, 32]. MED13, MED13L and MED12 form CDK8-module, which plays the key role in the regulation of Pol II mediated transcription [33]. Variants in MED13L and MED12 have been associated with different ID syndromes [34, 35]. The common phenotypic features for these disorders are ID and speech disturbances with variative eye abnormalities in case of MED12 mutations and ASD, facial dysmorphisms and heart defects in MED13L cases.

MED13-associated syndrome was firstly described by Lot Snijders Blok and colleagues and is characterized by DD and ID of various degrees, speech delay and other speech disorders with some 
variable features: ASD, attention deficit hyperactivity syndrome, eye abnormalities, mild facial dysmorphism [12]. Authors described 12 unique missense, nonsense and truncating pathogenic variants, located either in the N-terminal or C-terminal domains of MED13. There was no clear link between variation type or location and disease severity or phenotype feature set.

Repeat expansion in the FMR1 gene is the most common single gene mutation linked to ASD [36]. Additionally, copy number variants (CNVs) are one of the leading causes of DD, ID and ASD [37, 38]. Here we perform extensive genetic testing of the patients to primarily exclude these types of molecular defects, as WES analysis has limited ability to identify genetic variants of such types. The confirmation of the absence of fragile $X$ syndrome or pathogenic CNVs provides support in favor of the association of MED13 variants with the ASD phenotype.

Comparison of the patients described by Lot Snijders Blok and colleagues [12] and the patients in the current study shows that the most common phenotypic features are speech delay, which was present in all the patients, and DD of varying severity (borderline to moderate ID). Other frequently observed variable phenotypic features were behavioral disorders including ASD, ADHD or their combination, as well as overlapping facial characteristics: wide nose, high anterior hairline, flat philtrum, short palpebral fissures.

Interestingly, all the patients in our study were referred to the center due to ASD and/or speech delay and represent a rather mild spectrum of the MED13-associated disease. Additional phenotypic features were identified during reverse phenotyping and were pronounced very weakly. Nevertheless, comparison with the patients described by Lot Snijders Blok did not yield any clear correlation between the severity of the phenotype and variant's location or predicted impact and there was no apparent difference in phenotypes of the patients with short pathogenic variants disrupting MED13 and the patient with CNV loss of MED13.

Curiously, the only two patients in both studies presented with epilepsy had the only two de novo missense variants, situated outside of the $\mathrm{N}$-terminal or $\mathrm{C}$-terminal domains in the intrinsic disordered region. Both of these variants may affect phosphorylation of the nearby residues according to the computational predictions [39], which might be of functional importance [40].

Remarkably, in one of the families in our study and in one of the families in the study by Lot Snijders Blok, genetic variants in MED13 were inherited from the unaffected or mildly affected mothers. While the possibility that the genetic variant p.T292_P293del in family A is not causative can not be excluded, it does not seem likely, as it is a rare predicted pathogenic deletion of two aminoacids in a conserved region, where other genetic variants were described as pathogenic previously and proband's phenotype resembles closely phenotypic features of the MED13-associated DD. Despite no observation of the skewed expression of the mutant and wild-type alleles in the healthy carrier, the incomplete penetrance or variable expressivity of the phenotypic features by another mechanism cannot be ruled out.

\section{Limitations}


Our data strongly support the role of MED13 in the neurodevelopmental process. Functional studies are needed to distinguish likely pathogenic from non-pathogenic genetic variants. Study of alteration of the MED13 expression from maternal and paternal alleles is needed for maternally inherited genetic variants to elucidate its role in disease development. Mouse models with pathogenic amino acid substitutions introduced into the intrinsic disordered region are needed to confirm the hypothesis that pathogenic variants in this region are associated with seizures.

\section{Conclusion}

In this study we report four additional patients with pathogenic variants in MED13 and provide evidence that MED13 is a neurodevelopmental disorder-linked gene. The overlapping phenotypes of our patients are ASD, speech delay and mild dysmorphic features. One of the patients with a pathogenic amino acid substitution in the intrinsic disordered region exhibits epilepsy. Additionally we report a family with maternal transmission of the pathogenic allele.

Taken together our data have important implications for genetic diagnostics.

\section{List Of Abbreviations}

Neurodevelopmental disorders (NDDs)

Autism spectrum disorder (ASD)

Whole exome sequencing (WES)

Array comparative genomic hybridization (aCGH)

Polymerase chain reaction (PCR)

Attention deficit hyperactivity disorder (ADHD)

Intellectual disability (ID)

Copy number variants (CNVs)

Developmental delay (DD)

\section{Declarations}

\section{Ethics approval and consent to participate}

All procedures performed in studies involving human participants were in accordance with the ethical standards of the institutional and/or national research committee and with the 1964 Helsinki Declaration and its later amendments or comparable ethical standards. Ethical clearance was granted by the local 
ethics committee of Veltischev Research and Clinical Institute for Pediatrics of the Pirogov Russian National Research Medical University (№10, 17th October 2018). All the participants or their official representatives gave informed consent to participate in the study and to publish their anonymized individual data prior to participation in the study.

\section{Consent for publication}

Not applicable

\section{Availability of data and materials}

All additional data are available upon request

\section{Competing interests}

I.S.P., N.V.V., S.O.Zh., E.V.M., V.S.K., N.A.S., A.A.T., I.N.K., A.A.I., E.A.P. were employees of Genetico, Ltd. at the time of the study.

\section{Funding}

Not applicable

\section{Authors' contributions}

I.S.P., N.V.V., E.V.M., A.A.I., E.A.P. designed the study. I.S.P. led bioinformatic analysis and interpretation with assistance from S.O.Zh., I.N.K, V.S.K. for variant identification. N.V.V. led clinical assessment with assistance from E.V.M., E.A.P.. N.A.S., A.A.T, S.O.Zh., performed genetic tests. S.O.Zh., I.S.P. wrote the manuscript. All authors read and approved the manuscript.

\section{Acknowledgements}

We thank all participants of this study.

\section{References}

1. Vissers LE, Gilissen C, Veltman JA. Genetic studies in intellectual disability and related disorders. Nat Rev Genet. 2016 Jan 17(1):9-18. doi: 10.1038/nrg3999. Epub 2015 Oct 27.

2. Maulik PK, Mascarenhas MN, Mathers CD, Dua T, Saxena S. Prevalence of intellectual disability: a meta-analysis of population-based studies. Res Dev Disabil. 2011 Mar-Apr 32(2):419-36. doi: 10.1016/j.ridd.2010.12.018. Epub 2011 Jan 13.

3. Romeo R, Molosankwe I. Economic evidence in intellectual disabilities: a review. Curr Opin Psychiatry. 2010 Sep 23(5):427-31. doi: 10.1097/yco.0b013e32833ad946.

4. Lamsal R, Zwicker JD. Economic Evaluation of Interventions for Children with Neurodevelopmental Disorders: Opportunities and Challenges. Appl Health Econ Health Policy. 2017 Dec 15(6):763-772. 
doi: $10.1007 / s 40258-017-0343-9$.

5. Soden SE, Saunders CJ, Willig LK, Farrow EG, Smith LD, Petrikin JE, LePichon JB, Miller NA, Thiffault I, Dinwiddie DL, Twist G, Noll A, Heese BA, Zellmer L, Atherton AM, Abdelmoity AT, Safina N, Nyp SS, Zuccarelli B, Larson IA, Modrcin A, Herd S, Creed M, Ye Z, Yuan X, Brodsky RA, Kingsmore SF. Effectiveness of exome and genome sequencing guided by acuity of illness for diagnosis of neurodevelopmental disorders. Sci Transl Med. 2014 Dec;3 6(265):265ra168. doi:10.1126/scitranslmed.3010076.

6. Coe BP, Stessman HAF, Sulovari A, Geisheker MR, Bakken TE, Lake AM, Dougherty JD, Lein ES, Hormozdiari F, Bernier RA, Eichler EE. Neurodevelopmental disease genes implicated by de novo mutation and copy number variation morbidity. Nat Genet. 2019 Jan 51(1):106-116. doi: 10.1038/s41588-018-0288-4. Epub 2018 Dec 17.

7. Srivastava S, Love-Nichols JA, Dies KA, Ledbetter DH, Martin CL, Chung WK, Firth HV, Frazier T, Hansen RL, Prock L, Brunner H, Hoang N, Scherer SW, Sahin M, Miller, DT NDD Exome Scoping Review Work Group. Meta-analysis and multidisciplinary consensus statement: exome sequencing is a first-tier clinical diagnostic test for individuals with neurodevelopmental disorders. Genet Med. 2019 Nov;21(11):2413-21. doi:10.1038/s41436-019-0554-6. Epub 2019 Jun 11.

8. Calpena E, Hervieu A, Kaserer T, Swagemakers SMA, Goos JAC, Popoola O, Ortiz-Ruiz MJ, BarbaroDieber T, Bownass L, Brilstra EH, Brimble E, Foulds N, Grebe TA, Harder AVE, Lees MM, Monaghan KG, Newbury-Ecob RA, Ong KR, Osio D, Reynoso Santos FJ, Ruzhnikov MRZ, Telegrafi A, van Binsbergen E, van Dooren MF Deciphering Developmental Disorders Study, van der Spek PJ, Blagg J, Twigg SRF, Mathijssen IMJ, Clarke PA, Wilkie AOM. De Novo Missense Substitutions in the Gene Encoding CDK8, a Regulator of the Mediator Complex, Cause a Syndromic Developmental Disorder. Am J Hum Genet. 2019 Apr 4 104(4):709-720. doi: 10.1016/j.ajhg.2019.02.006. Epub 2019 Mar 21.

9. Yamamoto T, Shimojima K. A novel MED12 mutation associated with non-specific X-linked intellectual disability. Hum Genome Var. 2015 Jun 18 2:15018. doi: 10.1038/hgv.2015.18. eCollection 2015.

10. Lesca G, Moizard MP, Bussy G, Boggio D, Hu H, Haas SA, Ropers HH, Kalscheuer VM, Des Portes V, Labalme A, Sanlaville D, Edery P, Raynaud M, Lespinasse J. Clinical and neurocognitive characterization of a family with a novel MED12 gene frameshift mutation. Am J Med Genet A. 2013 Dec;161A(12):3063-71. doi:10.1002/ajmg.a.36162. Epub 2013 Aug 16.

11. Bouazzi H, Lesca G, Trujillo C, Alwasiyah MK, Munnich A. Nonsyndromic X-linked intellectual deficiency in three brothers with a novel MED12 missense mutation [c.5922G > T (p.Glu1974His)]. Clin Case Rep. 2015 Jul 3(7):604-9. doi: 10.1002/ccr3.301. Epub 2015 May 26.

12. Snijders Blok L, Hiatt SM, Bowling KM, Prokop JW, Engel KL, Cochran JN, Bebin EM, Bijlsma EK, Ruivenkamp CAL, Terhal P, Simon MEH, Smith R, Hurst J, McLaughlin H, Person R, Crunk A, Wangler MF, Streff H, Symonds JD, Zuberi SM, Elliott KS, Sanders VR, Masunga A, Hopkin RJ, Dubbs HA, OrtizGonzalez XR, Pfundt R, Brunner HG, Fisher SE, Kleefstra T, Cooper GM. De novo mutations in MED13, a component of the Mediator complex, are associated with a novel neurodevelopmental disorder. Hum Genet. 2018 May 137(5):375-388. doi: 10.1007/s00439-018-1887-y. Epub 2018 May 8. 
13. Adegbola A, Musante L, Callewaert B, Maciel P, Hu H, Isidor B, Picker-Minh S, Le Caignec C, Delle Chiaie B, Vanakker O, Menten B, Dheedene A, Bockaert N, Roelens F, Decaestecker K, Silva J, Soares G, Lopes F, Najmabadi H, Kahrizi K, Cox GF, Angus SP, Staropoli JF, Fischer U, Suckow V, Bartsch O, Chess A, Ropers HH, Wienker TF, Hübner C, Kaindl AM, Kalscheuer VM. Redefining the MED13L syndrome. Eur J Hum Genet. 2015 Oct;23(10):1308-17. doi:10.1038/ejhg.2015.26. Epub 2015 Mar 11.

14. Jiménez-Romero S, Carrasco-Salas P, Benítez-Burraco A. Language and Cognitive Impairment Associated with a Novel p.Cys63Arg Change in the MED13L Transcriptional Regulator. Mol Syndromol. 2018 Feb 9(2):83-91. doi: 10.1159/000485638. Epub 2018 Jan 11.

15. Tassone F, Pan R, Amiri K, Taylor AK, Hagerman PJ. A rapid polymerase chain reaction-based screening method for identification of all expanded alleles of the fragile X (FMR1) gene in newborn and high-risk populations. J Mol Diagn. 2008;10:43-9.

16. Sturm M, Schroeder C, Bauer P. SeqPurge: highly-sensitive adapter trimming for paired-end NGS data. BMC Bioinformatics. 2016 May 10 17:208. doi: 10.1186/s12859-016-1069-7.

17. Li H. Aligning sequence reads, clone sequences and assembly contigs with BWA-MEM. arXiv. 20131303.3997.

18. Li H, Handsaker B, Wysoker A, Fennell T, Ruan J, Homer N, Marth G, Abecasis G, Durbin R. 1000 Genome Project Data Processing Subgroup. The Sequence Alignment/Map format and SAMtools. Bioinformatics. 2009 Aug 15 25(16):2078-9. doi: 10.1093/bioinformatics/btp352. Epub 2009 Jun 8.

19. Mose LE, Perou CM, Parker JS. Improved indel detection in DNA and RNA via realignment with ABRA2. Bioinformatics. 2019 Sep 1 35(17):2966-2973. doi: 10.1093/bioinformatics/btz033.

20. Garrison E, Marth G. Haplotype-based variant detection from short-read sequencing. arXiv preprint, ArXiv:1207.3907 [q-bio.GN] (2012).

21. McLaren W, Gil L, Hunt SE, Riat HS, Ritchie GR, Thormann A, Flicek P, Cunningham F. The Ensembl Variant Effect Predictor. Genome Biol. 2016 Jun 6 17(1):122. doi: 10.1186/s13059-016-0974-4.

22. Karczewski KJ, Francioli LC, Tiao G, Cummings BB, Alföldi J, Wang Q, Collins RL, Laricchia KM, Ganna A, Birnbaum DP, Gauthier LD, Brand H, Solomonson M, Watts NA, Rhodes D, Singer-Berk M, England EM, Seaby EG, Kosmicki JA, Walters RK, Tashman K, Farjoun Y, Banks E, Poterba T, Wang A, Seed C, Whiffin N, Chong JX, Samocha KE, Pierce-Hoffman E, Zappala Z, O'Donnell-Luria AH, Minikel EV, Weisburd B, Lek M, Ware JS, Vittal C, Armean IM, Bergelson L, Cibulskis K, Connolly KM, Covarrubias M, Donnelly S, Ferriera S, Gabriel S, Gentry J, Gupta N, Jeandet T, Kaplan D, Llanwarne C, Munshi R, Novod S, Petrillo N, Roazen D, Ruano-Rubio V, Saltzman A, Schleicher M, Soto J, Tibbetts K, Tolonen C, Wade G, Talkowski ME Genome Aggregation Database Consortium, Neale BM, Daly MJ, MacArthur DG. The mutational constraint spectrum quantified from variation in 141,456 humans. Nature. 2020 May 581(7809):434-43. doi:10.1038/s41586-020-2308-7. Epub 2020 May 27.

23. Richards S, Aziz N, Bale S, Bick D, Das S, Gastier-Foster J, Grody WW, Hegde M, Lyon E, Spector E, Voelkerding K, Rehm, HL ACMG Laboratory Quality Assurance Committee. Standards and guidelines for the interpretation of sequence variants: a joint consensus recommendation of the American 
College of Medical Genetics and Genomics and the Association for Molecular Pathology. Genet Med. 2015 May;17(5):405-24. doi:10.1038/gim.2015.30. Epub 2015 Mar 5.

24. Yongwook Choi GE, Sims S, Murphy JR, Miller, Agnes P, Chan. Predicting the functional effect of amino acid substitutions and indels. PloS one, 7. (2012).

25. MacDonald JR, Ziman R, Yuen RK, Feuk L, Scherer SW. The database of genomic variants: a curated collection of structural variation in the human genome. Nucleic Acids Res. 2013 Oct 29.

26. Helen V, Firth, Shola M, Richards AP, Bevan S, Clayton M, Corpas D, Rajan S, Van Vooren Y, Moreau, Roger M, Pettett, Nigel P, Carter. DECIPHER: Database of Chromosomal Imbalance and Phenotype in Humans Using Ensembl Resources. Am J Hum Genet. 2009 Apr;84(4):524 - 33.

27. Ballif BC, Theisen A, Rosenfeld JA, Traylor RN, Gastier-Foster J, Thrush DL, Astbury C, Bartholomew D, McBride KL, Pyatt RE, and 14 others. Identification of a recurrent microdeletion at 17q23.1q23.2 flanked by segmental duplications associated with heart defects and limb abnormalities. Am. J. Hum. Genet. 86: 454-461, 2010.

28. Joanna S, Amberger. Ada Hamosh. Searching Online Mendelian Inheritance in Man (OMIM): A Knowledgebase of Human Genes and Genetic Phenotypes. Curr Protoc Bioinformatics. 2017 Jun 27;58:1.2.1-1.2.12.

29. Riggs ER, Andersen EF, Cherry AM, Kantarci S, Kearney H, Patel A, Raca G, Ritter DI, South ST, Thorland EC. Daniel Pineda-Alvarez, Swaroop Aradhya, Christa Lese Martin. Technical standards for the interpretation and reporting of constitutional copy-number variants: a joint consensus recommendation of the American College of Medical Genetics and Genomics (ACMG) and the Clinical Genome Resource (ClinGen). Genetics in Medicine volume 22, pages245-257(2020).

30. Sonia Pavan 1. Kathrin Rommel 2, María Elena Mateo Marquina 3, Sophie Höhn 1, Valérie Lanneau 1, Ana Rath. Clinical Practice Guidelines for Rare Diseases: The Orphanet Database. PLoS One. 2017 Jan 18;12(1):e0170365.

31. Yin JW, Wang G. The Mediator complex: a master coordinator of transcription and cell lineage development. Development. 2014 Mar 141(5):977-87. doi: 10.1242/dev.098392.

32. Miao YL, Gambini A, Zhang Y, Padilla-Banks E, Jefferson WN, Bernhardt ML, Huang W, Li L, Williams CJ. Mediator complex component MED13 regulates zygotic genome activation and is required for postimplantation development in the mouse. Biol Reprod. 2018 Apr;1 98(4):449-64. doi:10.1093/biolre/ioy004.

33. Knuesel MT, Meyer KD, Bernecky C, Taatjes DJ. The human CDK8 subcomplex is a molecular switch that controls Mediator coactivator function. Genes Dev. 2009 Feb 15 23(4):439-51. doi: 10.1101/gad.1767009.

34. Smol T, Petit F, Piton A, Keren B, Sanlaville D, Afenjar A, Baker S, Bedoukian EC, Bhoj EJ, Bonneau D, Boudry-Labis E, Bouquillon S, Boute-Benejean O, Caumes R, Chatron N, Colson C, Coubes C, Coutton C, Devillard F, Dieux-Coeslier A, Doco-Fenzy M, Ewans LJ, Faivre L, Fassi E, Field M, Fournier C, Francannet C, Genevieve D, Giurgea I, Goldenberg A, Green AK, Guerrot AM, Heron D, Isidor B, Keena BA, Krock BL, Kuentz P, Lapi E, Le Meur N, Lesca G, Li D, Marey I, Mignot C, Nava C, Nesbitt A, Nicolas 
G, Roche-Lestienne C, Roscioli T, Satre V, Santani A, Stefanova M, Steinwall Larsen S, Saugier-Veber P, Picker-Minh S, Thuillier C, Verloes A, Vieville G, Wenzel M, Willems M, Whalen S, Zarate YA, Ziegler A, Manouvrier-Hanu S, Kalscheuer VM, Gerard B, Ghoumid J. MED13L-related intellectual disability: involvement of missense variants and delineation of the phenotype. Neurogenetics. 2018 May;19(2):93-103. doi:10.1007/s10048-018-0541-0. Epub 2018 Mar 6.

35. Srivastava S, Niranjan T, May MM, Tarpey P, Allen W, Hackett A, Jouk PS, Raymond L, Briault S, Skinner C, Toutain A, Gecz J, Heath W, Stevenson RE, Schwartz CE, Wang T. Dysregulations of sonic hedgehog signaling in MED12-related X-linked intellectual disability disorders. Mol Genet Genomic Med. 2019;Apr7(4):e00569. doi:10.1002/mgg3.569. Epub 2019 Feb 6.

36. Flora Tassone,corresponding author Nimrah S, Choudhary F, Tassone B, Durbin-Johnson R, Hansen, Irva Hertz-Picciotto, and Isaac Pessah. Identification of Expanded Alleles of the FMR1 Gene in the CHildhood Autism Risks from Genes and Environment (CHARGE) Study. J Autism Dev Disord. 2013 Mar; 43(3): 530-539.

37. Matthew F, Pescosolido 1 ED, Gamsiz S, Nagpal, Eric M, Morrow. Distribution of disease-associated copy number variants across distinct disorders of cognitive development. J Am Acad Child Adolesc Psychiatry. 2013 Apr;52(4):414-30.e14.

38. Firth HV, et al., 2009. DECIPHER: Database of Chromosomal Imbalance and Phenotype in Humans using Ensembl Resources. Am.J.Hum.Genet 84, 524-533 doi: dx.doi.org/10/1016/j.ajhg.2009.03.010.

39. Li B, Krishnan VG, Mort ME, Xin F, Kamati KK, Cooper DN, Mooney SD, Radivojac P. Automated inference of molecular mechanisms of disease from amino acid substitutions. Bioinformatics. 2009;25:2744-50. doi:10.1093/bioinformatics/btp528.

40. Stieg DC, Willis SD, Ganesan V, Ong KL, Scuorzo J, Song M, Grose J, Strich R, Cooper KF. A complex molecular switch directs stress-induced cyclin $\mathrm{C}$ nuclear release through SCF(Grr1)-mediated degradation of Med13. Mol Biol Cell. 2018 Feb 1 29(3):363-375. doi: 10.1091/mbc.E17-08-0493. Epub 2017 Dec 6.

\section{Tables}

Due to technical limitations, Table 1 is only available as a download in the Supplemental Files section.

\section{Figures}




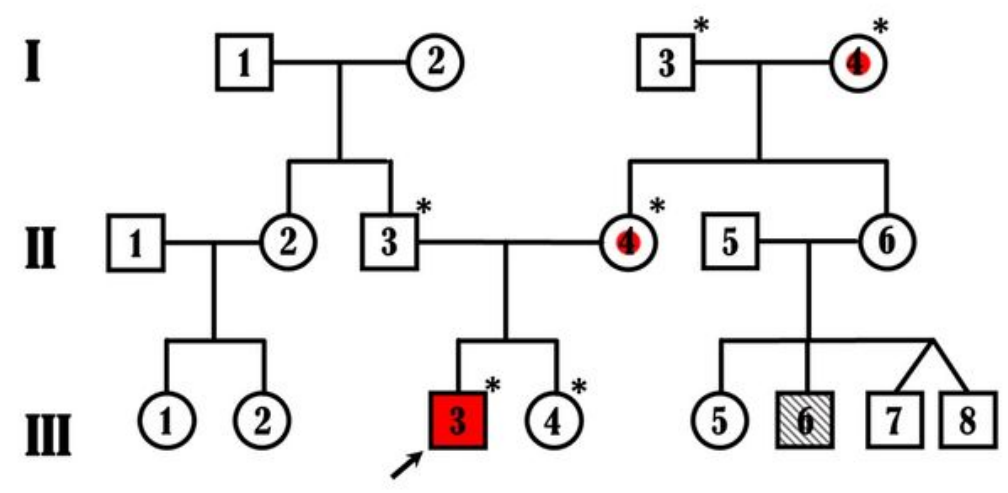

Family B

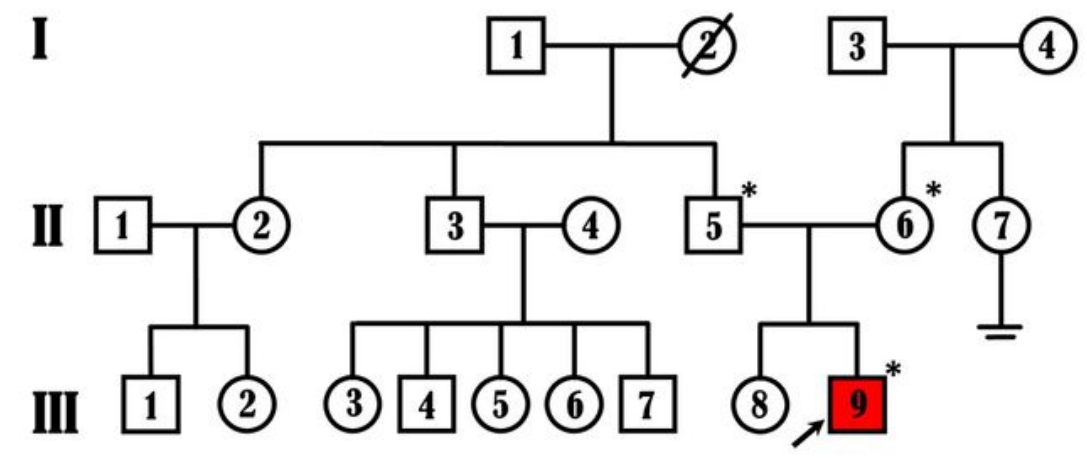

Family C

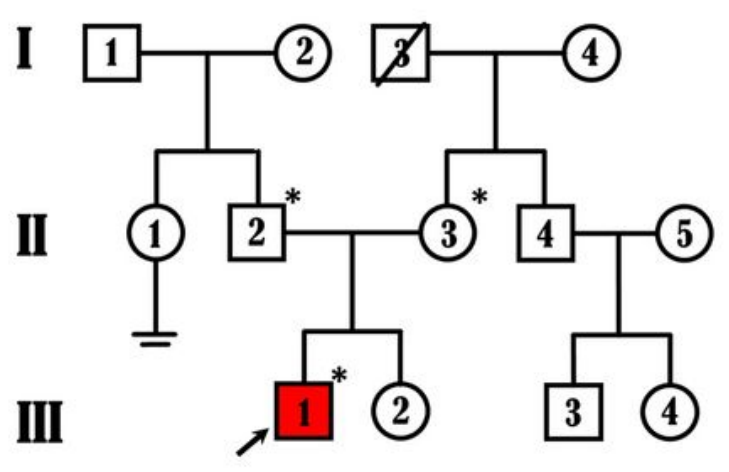

Family D

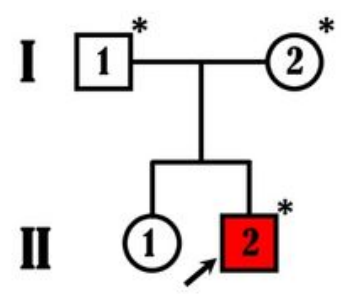

Figure 1

Pedigrees. Red color marks MED13 variant with phenotype (full filling) or without (center mark), grey hatch marks delay of speech development with unknown MED13 variant status, asterisk * marks sanger verification of the genetic variants revealed by WES. 


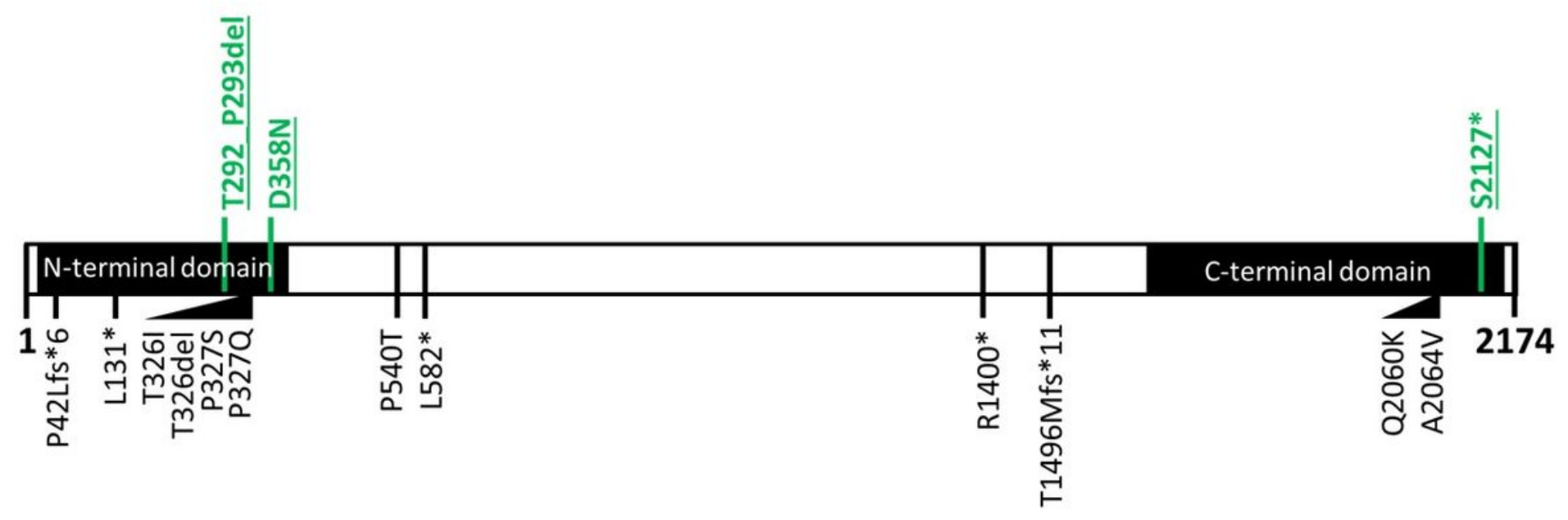

Figure 2

Protein location of short genetic variants revealed in our study (green bold) and in the study by Lot Snijders Blok (black).

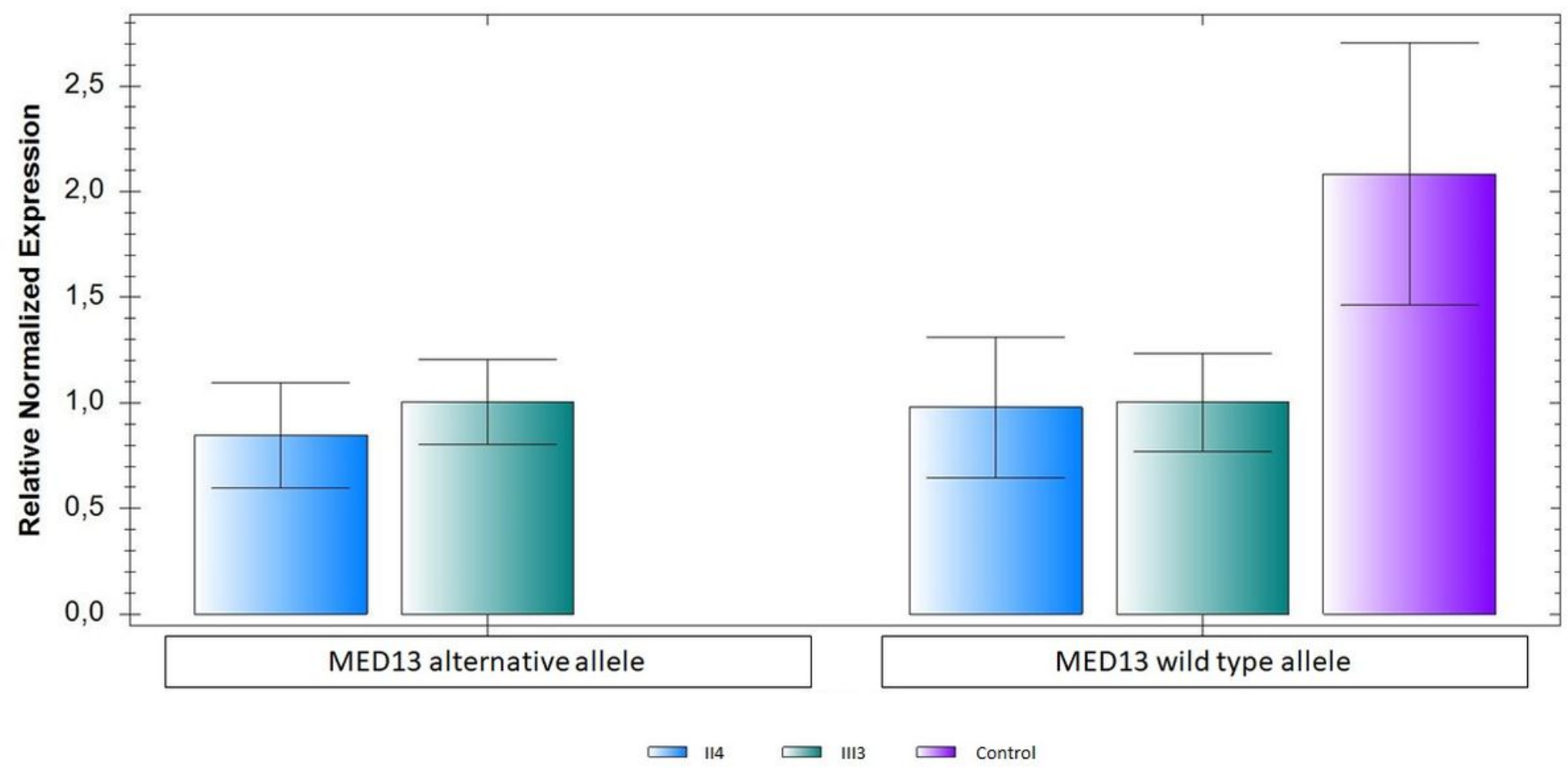

Figure 3

Results of allele specific expression analysis of p.T292_P293del variant in MED13 gene.

\section{Supplementary Files}


This is a list of supplementary files associated with this preprint. Click to download.

- Table1.docx

- Additionalfile1.docx 